\title{
Application of remote sensing data for measuring freshwater ecosystems changes below the Zeya dam in the Russian Far East
}

\author{
Oxana I. Nikitina ${ }^{1,2}$, Kirill Y. Bazarov ${ }^{3,4}$, and Evgeny G. Egidarev ${ }^{1,3}$ \\ ${ }^{1}$ World Wide Fund for Nature (WWF-Russia), Moscow, 109240, Russia \\ ${ }^{2}$ Water Problems Institute of the Russian Academy of Sciences, Moscow, 119333, Russia \\ ${ }^{3}$ Pacific Geographical Institute of the Far Eastern Branch of the Russian Academy of Sciences, \\ Vladivostok, 690041, Russia \\ ${ }^{4}$ Far Eastern Federal University, Vladivostok, 690090, Russia
}

Correspondence: Oxana I. Nikitina (onikitina@wwf.ru)

Received: 30 December 2017 - Revised: 28 February 2018 - Accepted: 2 March 2018 - Published: 5 June 2018

\begin{abstract}
The large Zeya hydropower dam is located on the Zeya River, the largest left-bank tributary of the Amur-Heilong River in Russia. The dam had been constructed by 1980 and its operation has significantly transformed the flow regime of the Zeya River. The flow regulation has reduced the magnitude of periodic flooding of the floodplain areas located downstream from the Zeya dam and disrupted habitats of flora and fauna. An estimation of the transformation of the freshwater ecosystems is required to develop measures necessary either to maintain or restore disrupted ecosystems. Application of remote sensing methods allows measuring characteristics of the ecosystem's components. Two sections of a floodplain below the Zeya dam were considered for analysis in order to detect changes in objects at each site during the comparison of remote data from 1969/1971 and 2016.
\end{abstract}

\section{Introduction}

The Amur-Heilong River, one of the ten largest rivers on Earth, flows in Northeast Asia through Mongolia, China and Russia. The large-scale Zeya hydropower dam is located on the Zeya River which is the largest left-bank tributary of the Amur-Heilong in the Russian Far East. The location of the basin and the dam are shown in Fig. 1. The construction of the Zeya dam began in 1964, the reservoir created by the dam was filled between 1974 and 1980 .

The environmental consequences of large dams include changes of hydrological regime and sediment runoff, fragmentation of the basin, flooding of lands and transformation of the natural ecosystem dynamics in the areas located upstream and downstream of dams (Nilsson et al., 2005; Dams and Development, 2000). River damming provides a considerable impact on downstream freshwater ecosystems in many cases extending for hundreds of kilometres below a dam (Richter and Thomas, 2007; Podolsky et al., 2006). The territory affected by the Zeya dam comprises biologically diverse areas which depend upon the hydrological regime of the floodplain (Simonov et al., 2016; Nikitina et al., 2015). Sections of the Zeya's floodplain are important stopovers for migratory birds along their routes (Simonov and Dahmer, 2008). Wetlands of the Muraviovka Park for Sustainable Land Use are included in the List of Wetlands of International Importance (the Ramsar List); they are affected by the flow regimes of the Amur and Zeya rivers (Smirenski, 2016).

Periodic flooding of the floodplain is an essential ecohydrological indicator of both the flow regime and the quality and productivity of floodplain areas (Fashchevsky, 2007). The flow regulation has reduced the magnitude of periodic flooding of the floodplain areas located downstream from the Zeya dam and has also disrupted habitats of flora and fauna. As shown in Fig. 2, under natural conditions, small floods used to occur almost annually at the Belogorye stream gauge located $617 \mathrm{~km}$ downstream. These used to last anything from 19 to 58 days. However, under flow regulation, 


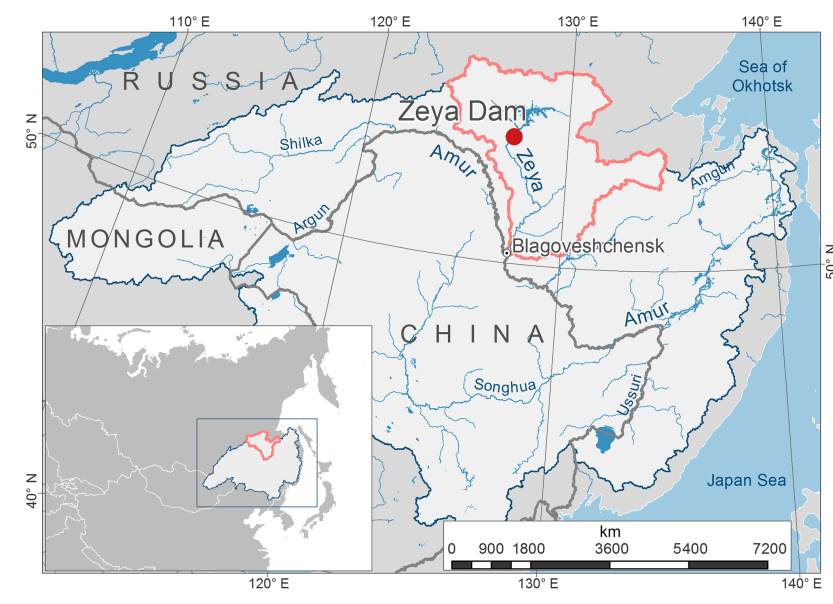

Figure 1. Map of the Amur River basin showing the location of the Zeya River basin and the Zeya dam.

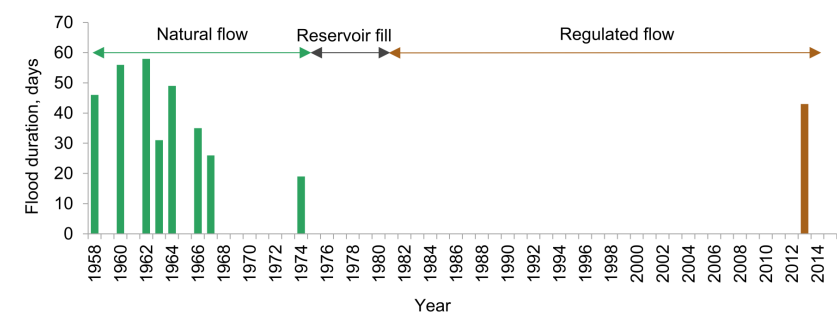

Figure 2. Changes in flood duration at the Belogorye stream gauge located $617 \mathrm{~km}$ downstream from the Zeya dam.

floods have now practically disappeared. Reduction of maximum flow magnitude and duration leads not only to the degradation of freshwater habitats and floodplain's ecosystems but also to changes in the composition of vegetation. The extent of changes depends on the degree of river flow regulation, specifically on the level, time and duration of natural floods and released water from reservoirs (Fashchevsky, 2007).

An estimation of the transformation of the freshwater ecosystems is required to develop measures necessary either to maintain or restore disrupted ecosystems. The application of remote sensing methods allows us to estimate the characteristics of the components of the ecosystem (Dorber et al., 2018; Kravtsova, 1995). These characteristics can serve as a basis for an assessment of changes in the freshwater ecosystems.

The research aims to identify and analyse the trend and intensity of changes in the components of the floodplain located below the Zeya dam when they are exposed to its impact. The initial assumption is that flow regulation by the dam has had a decisive effect on the changes in the ecosystems. Other possible and additional factors affecting transformation of the ecosystems include climate change, development of agriculture and fires.

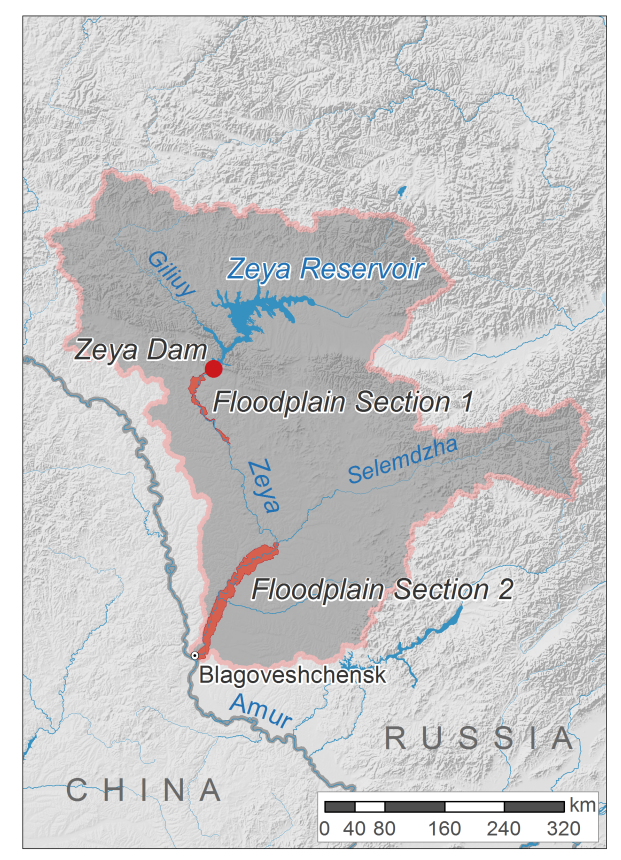

Figure 3. Location of the wide floodplain sections described in this article.

\section{Materials and methods}

The methodology involves estimation of spatiotemporal changes of components located within the wide floodplain of the Zeya River downstream from the dam. Due to its size, the wide floodplain serves as a habitat for numerous species of birds, fish and other animals; it is crucial to the biodiversity of the freshwater ecosystem.

Expert interpretation using 1:100000 topographic maps revealed the borders of the floodplain where flooding rarely occurs (approximately once in fifty years) (Egidarev, 2012; Farr et al., 2000). Two sections of a wide floodplain located below the Zeya dam were considered during the analysis as shown in Fig. 3. The first section is located in the immediate vicinity of the Zeya dam; its length is $140 \mathrm{~km}$ with a maximum width of $17 \mathrm{~km}$. The second section begins $350 \mathrm{~km}$ away from the dam of the Zeya hydropower station below the confluence of the Selemdzha River (the Zeya's biggest tributary) and ends in the estuary of the Zeya; the length of the section is $200 \mathrm{~km}$, its maximum width being $23 \mathrm{~km}$.

With the use of ArcGIS 10.5 software and remote imageries, two thematic layers that are demonstrated in Fig. 4 have been created. These layers represent both archive (1969/1971) and contemporary (2016) pictures with a scale of $1: 50000$, reflecting the structure and changes of the land cover in two sections of the wide floodplain located downstream from the Zeya dam.

The retrospective state is represented by archival imageries from missions flown by the CORONA, ARGON and LANYARD satellite systems. Mosaics are collected from im- 


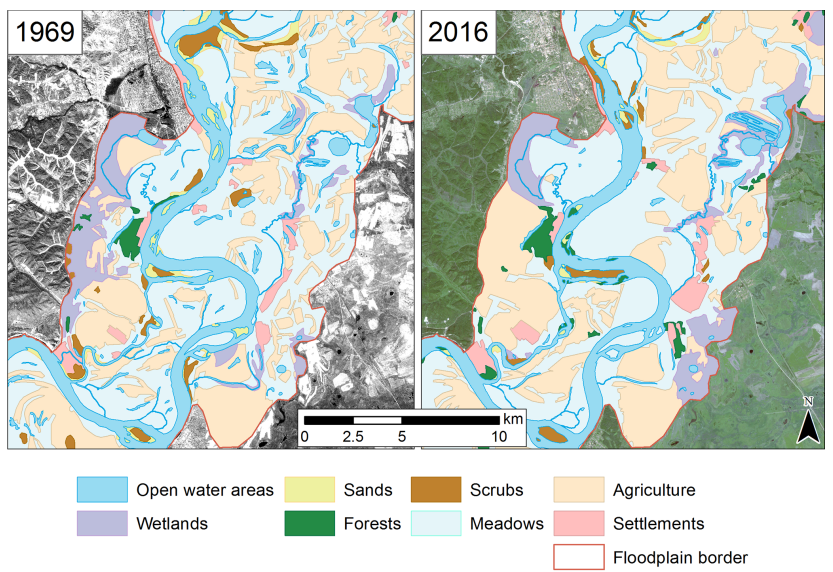

Figure 4. Land cover of the floodplain sections identified for the analysis.

ageries dated 23 September 1969 and 14 September 1971. The imageries of 1969 and 1971 reflect the state of the area and are typical of the Zeya River's natural (little disrupted) flow regime. The contemporary picture is presented by images captured by the Sentinel-2 satellite. The mosaics of the images, obtained on 11 September 2016, were created for the study area.

Two basic maps reflecting land usage during the 2002 and 2016 vegetation periods were created on the basis of the ArcGIS 10.5, and remote data collected by the Landsat satellite were analyzed.

Indicators of Hydrologic Alteration software were used to calculate the characteristics of both the natural and altered flow regimes shown on Fig. 2. Sets of observations for the Belogorye stream gauge for the period 1957-2013 were used to detect hydrologic alteration. Two distinct time periods of daily water discharge were compared to analyse how the flow regime was affected: (1) 1957-1975 - pre-impact regime; (2) 1980-2013 - post-impact regime.

\section{Preliminary results}

The interpretation of both archive and contemporary images revealed different water conditions: 2016 was a wet year compared with 1969 and 1971, with increased river inflow into the Zeya below the dam; the difference is pronounced in the second section of the floodplain in the lower reaches of the Zeya.

Table 1 presents data on the total area of the objects and the changes which occurred to the sections of a wide floodplain in 1969-2016. The area of the objects under the natural flow regime (in 1969/1971) was taken as $100 \%$ when the relative figures were calculated. The examples of revealed differences between floodplain objects of 1969/1971 and 2016 are demonstrated in Fig. 5.
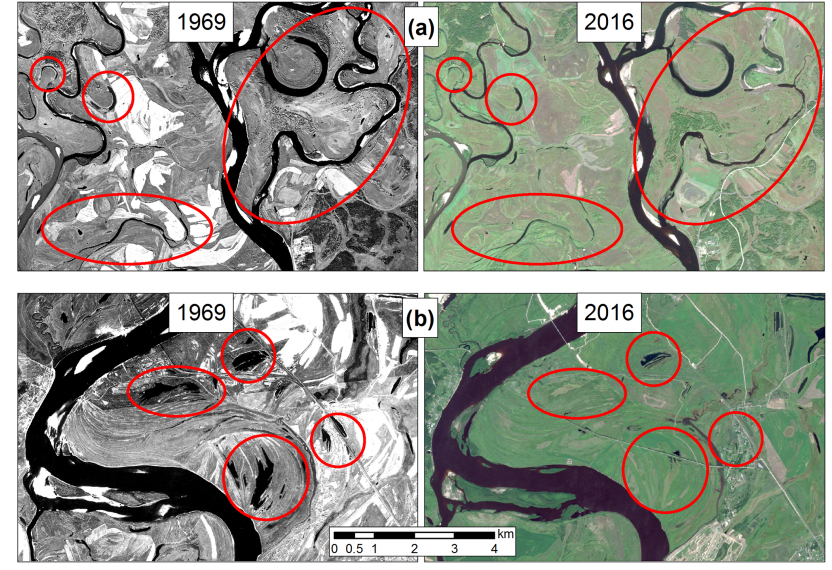

Figure 5. Examples of the changes in the floodplain objects. Red circles mark the differences detected for water bodies: (a) a river channel that has become a chain of oxbow lakes; the surface area of the lakes has been reduced in the Floodplain Section 1; (b) the surface area of the lakes has been reduced in the Floodplain Section 2.

\subsection{Change of objects in the Floodplain Section 1}

The surface area of the floodplain and oxbow lakes has reduced from 950 to 617 hectares (35\%). Supposedly, the main reason for this reduction is the absence of periodic flooding in the floodplain due to river flow regulation by the Zeya dam combined with the reduced level and duration of natural floods. Another additional factor could be climate change. A comparison of regional trend estimates for the two periods 1976-2006 and 1976-2012 has revealed a trend of temperature rise $\left(+0.44^{\circ} \mathrm{C} / 10\right.$ years $)$ in the Amur region; however, this trend is statistically insignificant at a level of $5 \%$. The average amounts of precipitation for the periods of 19362010 and 1976-2010 demonstrate that the areas with trends of decreasing annual and summer precipitation predominate in the Amur region but the percentage of their decrease is insignificantly small (Katsov et al., 2014). These remarks are consistent with the assumption that climate change has not been the principal reason for changes in the floodplain objects.

Water discharges at the lower reaches of the Zeya dam in wet season of 2016 were lower than the water discharges observed under the natural (little disrupted) flow regime in 1969. This is typical of regulated flow regime of Zeya and explains the reduced area of the Zeya River's main channel in 2016. Small tributaries and river branches within the floodplain were also reduced by 2016 with some of them changing from a continuous stream into a chain of oxbow lakes.

The meadows area has increased from 33.7 to 38.8 thousand hectares. This is mainly due to previously farmed but currently abandoned agricultural fields being turned into meadows. The forest area of the floodplain has seen a $70 \%$ growth from 3.2 to 5.5 thousand hectares. It confirms the thesis of Martynov (2013) that changes in flood regime, or 
Table 1. Land cover in the study area for the time period 1969-2016.

\begin{tabular}{|c|c|c|c|c|c|c|c|c|}
\hline \multirow[t]{2}{*}{ Object types } & \multicolumn{4}{|c|}{ Floodplain Section 1} & \multicolumn{4}{|c|}{ Floodplain Section 2} \\
\hline & $\begin{array}{l}\text { Area in } \\
1969 / 1971 \\
\text { (ha) }\end{array}$ & $\begin{array}{l}\text { Area in } \\
2016 \\
\text { (ha) }\end{array}$ & $\begin{array}{l}\text { Area } \\
\text { changes in } \\
\text { 1969-2016 } \\
\text { (ha) }\end{array}$ & $\begin{array}{l}\text { Area } \\
\text { changes in } \\
1969-2016 \\
(\%)\end{array}$ & $\begin{array}{l}\text { Area in } \\
1969 / 1971 \\
\text { (ha) }\end{array}$ & $\begin{array}{l}\text { Area in } \\
2016 \\
\text { (ha) }\end{array}$ & $\begin{array}{l}\text { Area } \\
\text { changes in } \\
1969-2016 \\
\text { (ha) }\end{array}$ & $\begin{array}{l}\begin{array}{l}\text { Area } \\
\text { changes in } \\
1969-2016 \\
(\%)\end{array} \\
\text { \%) }\end{array}$ \\
\hline Lakes & 950 & 617 & -332 & -35.0 & 5109 & 2932 & -2177 & -42.6 \\
\hline Wetlands & - & - & - & - & 30883 & 19588 & -11296 & -36.6 \\
\hline Rivers & 8343 & 7537 & -805 & -9.7 & 28532 & 30593 & 2061 & 7.2 \\
\hline Sands & 929 & 937 & 8 & 0.9 & 7346 & 839 & -6508 & -88.6 \\
\hline Meadows & 33666 & 38841 & 5175 & 15.4 & 127747 & 137892 & 10144 & 7.9 \\
\hline Forests & 3244 & 5521 & 2276 & 70.2 & 1396 & 5325 & 3929 & 281.5 \\
\hline Scrubs and trees & 4005 & 3105 & -900 & -22.5 & 5259 & 10292 & 5033 & 95.7 \\
\hline Settlements & 1951 & 2172 & 220 & 11.3 & 3785 & 5608 & 1823 & 48.2 \\
\hline Agriculture & 14628 & 8999 & -5629 & -38.5 & 48984 & 45732 & -3252 & -6.6 \\
\hline Total area & 67717 & 67730 & 13 & 0.02 & 259041 & 258800 & -241 & -0.1 \\
\hline
\end{tabular}

disappearance of floods lead to an acceleration of vegetation fluctuations in the floodplain, ultimately resulting in the emergence of forests or steppe meadows. The scrubs and trees area has been reduced from 4 to 3.1 thousand hectares; some of these objects have turned into forests.

The settlements area has grown from 1.9 to 2.1 thousand hectares. A comparison between contemporary and archive images has revealed a significant reduction of farmed lands area from 14.6 to 9.0 thousand hectares. This is due to the active development of virgin lands in 1954-1965 that was undertaken to increase grain production when large areas of such lands were ploughed in the various states of the former Soviet Union. This included the Russian Far East, the Zeya's floodplain being amongst them. Floodplains typically boast fertile land with high crop capacity which makes them highly suitable for efficient agriculture. The expansion of farmed land area for soya growth continued throughout the period under consideration (i.e. 1969/1971). The crisis which began in the 1980s has led to a reduction of the farmlands revealed during the analysis.

\subsection{Change of objects in the Floodplain Section 2}

2016 was a wet year compared to 1969: the tributaries flowing into the Zeya were abundant forming wetlands in some of the mouth sections. This explains the $7.2 \%$ increase in the rivers' water surface: even given the regulation of the Zeya flow higher upstream, high water discharges were noted compared to the unaltered flow regime of 1969 . Obviously in its lower reaches, the Zeya is less dependent on the hydropower station's operating mode due to the effect of the large freeflowing tributary - the Selemdzha which flows into the Zeya at the beginning of the floodplain section. At the same time, the smaller floodplain streams have reduced which indicates changing overall flooding conditions in the floodplain.

The water surface of the lakes has seen a $43 \%$ drop from 5.1 to 2.9 thousand hectares; the wetland area - a $36 \%$ drop from 30.8 to 19.6 thousand hectares. Despite the significant impact of the large tributary Selemdzha, the Zeya floodplain's flooding regime has changed in the river's lower reaches as well.

The meadows area has grown from 127.7 to 137.9 thousand hectares $(7.9 \%)$ due to abandoned farmlands being turned into meadows. The forest area has almost quadrupled (from 1.4 to 5.3 thousand hectares). The scrubs and trees area has nearly doubled in size, from 5.3 to 10.3 thousand hectares; such changes could happen due to frequent fires. According to the global fire monitoring program and the archive data (Giglio et al., 2016), about 4.5 thousand sites of fire were registered in the lower reaches of the river Zeya throughout the previous decade only (in 2006-2016). Due to this permanent pyrogenic factor, the dominant vegetation type is changing from forest to arboreal and shrubby; the species composition of flora and fauna alike is becoming less diverse.

The settlements area has grown from 3.8 to 5.6 thousand hectares. The farmlands area has reduced insignificantly (a $6.6 \%$ reduction from 49.0 to 45.7 thousand hectares): development of virgin lands and the ploughing of large land areas were major activities in 1969/1971. However, since the early 2000s, the farmed land area in the lower reaches of the Zeya River has grown again. Calculations based on the remote data collected by the Landsat satellite revealed that arable land area had doubled between 2002 and 2016, from 14.5 to 29.8 thousand hectares. The area of abandoned agricultural lands, including the so-called fallow lands (ploughed and weeds-free but not sown) has grown too, from 8 thousand hectares in 2002 to 13.7 thousand in 2016. The analysis confirms the thesis that flow regulation and flood control lead to the transformation of natural ecosystems caused by the subsequent active development of agriculture (Brykina, 2017; Shalikovsky and Kurganovich, 2011). 


\section{Conclusions}

Large dams affect freshwater ecosystems and cause extensive environmental impacts downstream from the dam. The alteration of the freshwater ecosystems affects the floodplain habitats of flora and fauna and causes changes in land use; this can lead to biodiversity loss. Remote sensing data is useful for monitoring surface area of the objects and their changes. As for the study area, the surface areas of lakes in both floodplain sections of the Zeya River have decreased in size which likely indicates that the landscape is changing due to the changed flow regime. Small streams of the floodplain have also reduced, with some of them turning from a continuous stream into a chain of oxbow lakes. The wetland area has significantly decreased in the second floodplain section. The impact of the dam in the lower reaches of the Zeya is less pronounced due to the long distance from the dam and the increased lateral inflow. The forest area has grown in both sections; a possible explanation for this being the accelerated vegetational fluctuations in the floodplain due to the changed flow regime. The abandoned agricultural lands have mostly become meadows and it explains the growth of meadow territories in both sections. The conducted study can serve as a basis to assess the impact of the Zeya dam operation on the biodiversity of the freshwater ecosystems of the AmurHeilong basin.

Data availability. The majority of the data presented in the article is from an ongoing project. The complete data set will be made public on the Amur information center, a web portal hosted by Amur Branch of WWF-Russia. Further information can be obtained from Oxana I. Nikitina.

Competing interests. The authors declare that they have no conflict of interest.

Special issue statement. This article is part of the special issue "Innovative water resources management - understanding and balancing interactions between humankind and nature". It is a result of the 8th International Water Resources Management Conference of ICWRS, Beijing, China, 13-15 June 2018.

Acknowledgements. We would like to express our gratitude to Mikhail V. Bolgov, Water Problems Institute of the Russian Academy of Sciences, for his advice on this research.

The work was funded by World Wide Fund for Nature (WWFRussia).

Edited by: Dingzhi Peng

Reviewed by: two anonymous referees

\section{References}

Brykina, I. G.: Agricultural use of floodplains under river regulation, Agricultural Sciences for Agriculture, Publishing House of Altay State Agrarian University, 406-406, 2017.

Dams and Development: A New Framework For Decision-Making, The Report Of The World Commission On Dams, Earthscan Publications Ltd, London and Sterling, VA, 2000.

Dorber, M., May, R., and Verones, F.: Modeling Net Land Occupation of Hydropower Reservoirs in Norway for Use in Life Cycle Assessment, Environ. Sci. Technol., 52, 2375-2384, https://doi.org/10.1021/acs.est.7b05125, 2018.

Egidarev, E. G.: Mapping and estimation of floodplain complexes in the Amur River valley, Vestnik of the Far East Branch of the Russian Academy of Sciences, 2, 9-16, 2012.

Farr, T. G., Hensley, S., Rodriguez, E., Martin, J., and Kobrick, M.: The shuttle radar topography mission, CEOS SAR Workshop, Toulouse, 26-29 October 1999, Noordwijk, 361-363, 2000.

Fashchevsky, B. V.: Ecological value of floodplains in riverine ecosystems, Russian State Hydrometeorological University Proceedings, 5, 118-129, 2007.

Giglio, L., Schroeder, W., and Justice, C.O.: The collection 6 MODIS active fire detection algorithm and fire products, Remote Sens. Environ., 178, 31-41, 2016.

Katsov, V. M., Semenov, S. M., Alekseev, G. V., Ananicheva, M. D., et al.: Second Roshydromet Assessment Report on Climate Change and its Consequences in the Russian Federation, Moscow, Roshydromet, 2014.

Kravtsova, V. I.: Space mapping techniques, Publishing House of Moscow State University, Moscow, 1995.

Martynov, A. V.: Soil cover structure of bottomland of major rivers in the Amur Region (exemplified by the Zeya and Selemdja rivers), Bulletin of the North-East Scientific Center, Russian Academy of Sciences, Far East Branch, 2, 108-116, 2013.

Nikitina, O. I., Simonov, E. A., and Egidarev, E. G.: River flood adaptation in the Amur basin and nature conservation, Use and Protection of Natural Resources of Russia, 3, 15-24, 2015.

Nilsson, C., Reidy, C. A., Dynesius, M., and Revenga, C.: Fragmentation and flow regulation of the world's large river systems, Science, 308, 405-408, 2005.

Podolsky, S. A., Simonov, E. A., and Darman, Yu. A.: Where does the Amur flow?, WWF-Russia, 2006.

Richter, B. D. and Thomas, G. A.: Restoring environmental flows by modifying dam operations, Ecol. Soc., 12, 12, http://www. ecologyandsociety.org/vol12/iss1/art12/, 2007.

Shalikovsky, A. V. and Kurganovich, K. A.: Hazard and risk assessment for commercial use of the Upper and Middle Amur basin floodplains, Transbaikal State University Journal, 11, 119-124, 2011.

Simonov, E. A. and Dahmer, T. D.: Amur-Heilong River Basin Reader, Hong Kong, Ecosystems Ltd, 2008.

Simonov, E. A., Nikitina, O. I., Osipov, P. O., Egidarev, E. G., and Shalikovsky, A. V.: We and the Amur floods: Lesson (Un)Learned?, WWF-Russia, 2016.

Smirenski, S. M. (Ed.): Giltchin river watershed, History. Wetlands. Water resources, Dalnauka, Vladivostok, 2016. 